\title{
Gastro-Intestinal Stromal Tumour presenting as Gastroduodenal Intussusception
}

\author{
Taori K, Rathod J, Disawal A, Parate R, Hatgaonkar A, Mane S
}

Department of Radiodiagnosis, Government Medical College \& Hospital, Nagpur, India

\begin{abstract}
Gastrointestinal stromal tumours (GISTs), are relatively common tumours of the gastrointestinal tract, most commonly found in the stomach. Previously they were termed as leiomyomas and leiomyosarcomas. Clinically, they are asymptomatic but may cause abdominal pain or bleeding from ulceration of the overlying mucosa. We present a case of gastroduodenal intussusception secondary to large gastric stromal tumour in a 50 year old male, which presented with intermittent abdominal pain and gastric outlet obstruction. Preoperative diagnosis was made on abdominal CT and confirmed at laparotomy.
\end{abstract}

Keywords: Gastroduodenal Intussusception, Gastrointestinal Stromal Tumours, CT abdomen, Laparotomy, Bowel within Bowel Configuration.

\section{Introduction}

Gastrointestinal stromal tumours (GISTs) are relatively common tumours of the stomach, occurring in up to $46 \%$ of stomach in some post mortem series. ${ }^{1}$ Previously referred to as leiomyomas and leiomyosarcomas, recently they have been reclassified as arising from undifferentiated stromal fibroblasts rather than mature smooth muscle cells. ${ }^{2}$ Their size can vary ranging from $0.5 \mathrm{~cm}$ to $30 \mathrm{~cm}$ in diameter. Around three-quarters of these tumours are benign, however risk of malignancy rises as size increases. The malignant transformation can be upto $60 \%$ of tumours when tumour size is over $10 \mathrm{~cm}$

Corrospondence to: Dr. Shashikant Raghunath Mane, Harishchandra", Sainagar, Ashta, Taluka- Walwa, Sangli, Maharashtra, India. Email:-shashimane123@gmail.com
(Usually determined by the histological presence of more than five mitotic figures per 10 high power fields). Age is also a relevant factor, with GISTs common in those between 50 and 60 years of age, and less common in those aged 40 years or younger. The majority of GISTs are asymptomatic, with a large proportion being found incidentally at autopsy or during other surgical procedures. Ulceration of the apical mucosa may occur resulting in abdominal pain and bleeding, which is present in up to $50 \%$ of benign tumours and $85 \%$ of malignant tumours. ${ }^{3}$ Less commonly, patients may complain of weight loss, a palpable mass, early satiety, dysphagia and vomiting. ${ }^{4}$

Gastroduodenal intussusception is rare complication of GISTs \& is caused by prolapse of the tumour and subsequent invagination of a portion or the full thickness 
of the gastric wall into the duodenum. ${ }^{5}$ Usually patient complains of intermittent vague epigastric pain. Very rarely it can present as an acute gastrointestinal emergency with severe sudden pain, shock and intractable vomiting. Intermittent symptoms due to recurrent, spontaneously reducible intussusceptions have been reported. $^{5}$ An epigastric mass may be palpated on physical examination. Endoscopy, ultrasound, barium studies \& CT abdomen examination have been used to demonstrate this rare complication of a GIST.

\section{Case Report}

A 50 years old male presented with history of recurrent episodes of indigestion and recent history of intermittent severe epigastric pain, premature fullness and nonbile stained vomiting and undigested food. Between these episodes the patient was well. On examination, there was mild tenderness in the epigastrium but no mass was palpable. All haematological and biochemical indices were normal.

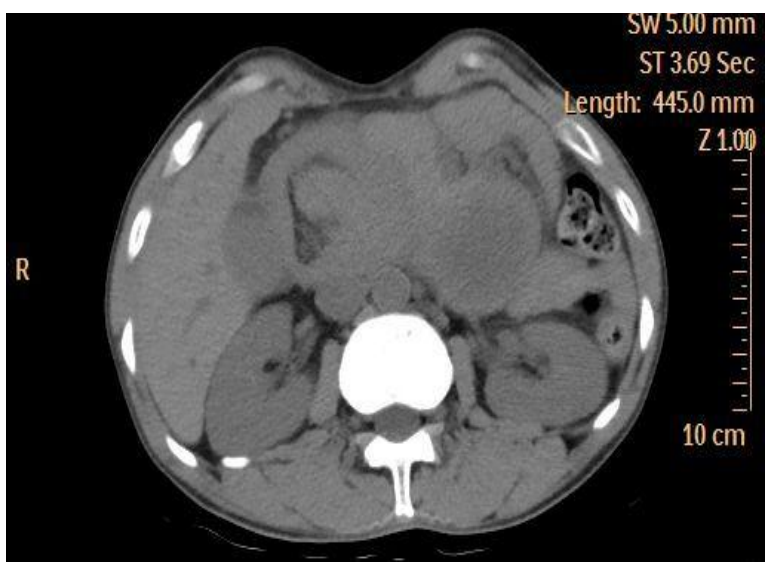

Fig. 1: CT abdomen plain study showing telescoping of antropyloric portion of stomach along with its lesser \& greater omentum into first \& second part of duodenum giving "CT target sign" with no obvious calcifications.

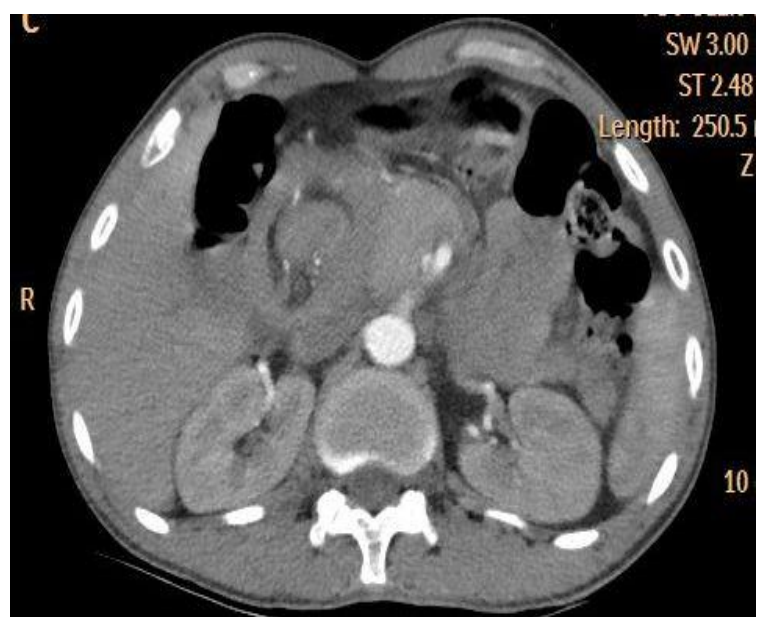

Fig. 2: CT abdomen contrast study showing telescoping of antropyloric portion of stomach along with its lesser \& greater omentum into first \& second part of duodenum giving "CT target sign" with mesenteric vessels around intussusceptum.

Abdominal ultrasound revealed a dilated stomach, despite fasting, and mixed echogenic lesion in the region of the duodenum, suggesting gastric outflow or duodenal obstruction. CT was requested for further evaluation.

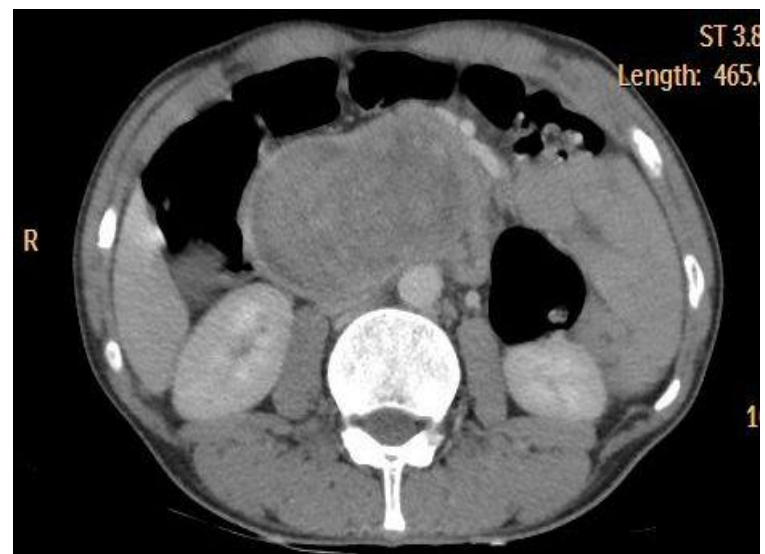

Fig. 3: CT abdomen contrast study reveals well defined moderately heterogeneously enhancing lesion acting as its lead point possibly gastric stromal tumour.

CT examination confirmed partial gastric outflow obstruction with a characteristic pattern of intussusception, four layers of 
bowel wall at the second \& third part of duodenum which is surrounded by rim of low density tissue compatible with fat (Fig. $1,2,4 \& 5)$.

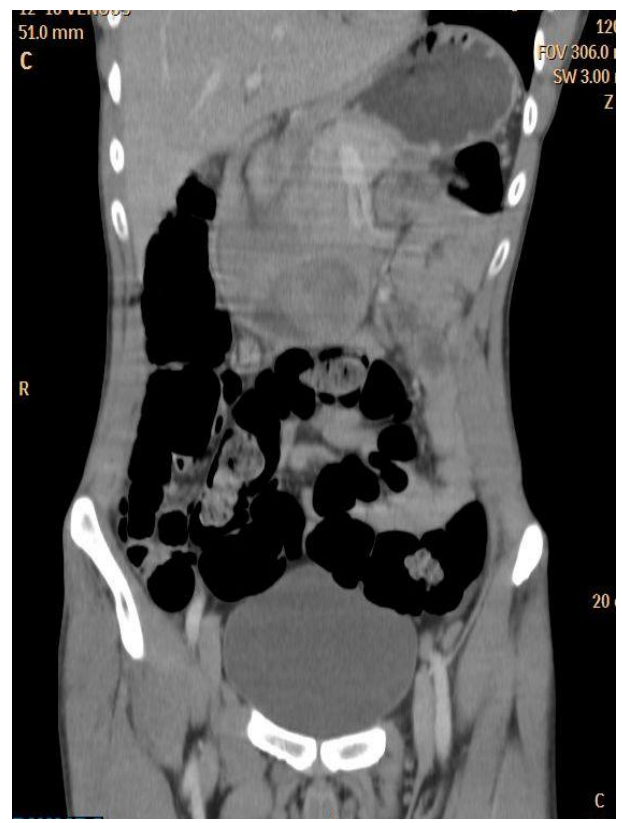

Fig.4:CT abdomen coronal reconstruction reveals, bowel within bowel configuration along with mesenteric vessels s/o gastroduodenal intussusception.

A well-defined moderately heterogeneously enhancing 6.7 X $5.2 \times 7 \mathrm{cms}$ mass lesion, was present in the region of the second $\&$ third part of the duodenum acting as lead point (Fig. 3). Although extremely rare, a diagnosis of intussusception of a GIST was suggested. At laparotomy, third part of the duodenum was distended by a hard mass. Manipulation of the mass delivered it into the stomach and a simple gastrotomy revealed a $5 \times 4 \mathrm{~cm}$ stromal tumour on a long pedicle derived from the mucosa of the anterior gastric antrum. The base of the tumour was excised and the gastrotomy closed. There was no evidence of metastatic spread. The patient made an uneventful postoperative recovery. Histology confirmed the preoperative diagnosis.

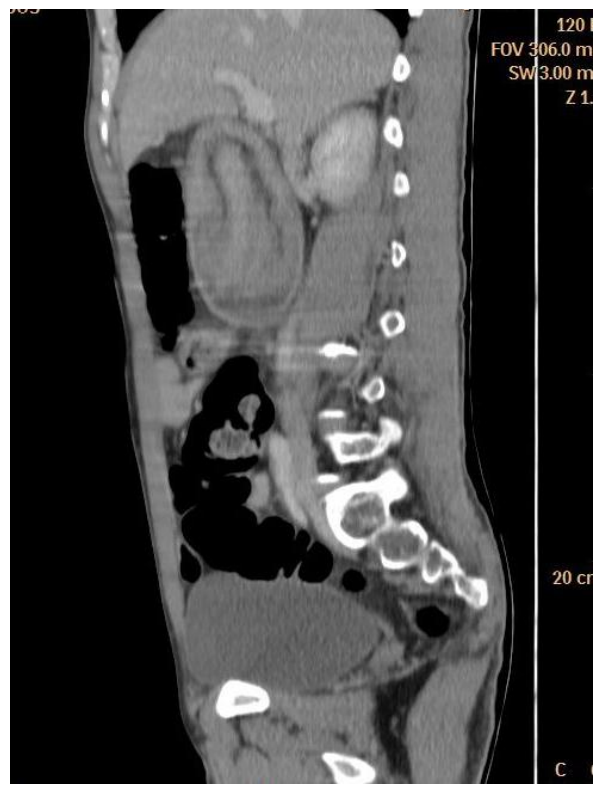

Fig. 5:CT abdomen sagittal reconstruction reveals, bowel within bowel configuration along with mesenteric vessels s/o gastroduodenal intussusception.

\section{Discussion}

The first report of intussusception was made in 1674 by Barbette of Amsterdam '. Intussusception or "introsusception" as it was called then, was in addition detailed in 1789 by John Hunter. ${ }^{7}$ In 1871 Sir Jonathan Hutchinson was the first to successfully operate on a child with intussusception. ${ }^{8}$ Intussusception in adults differs from those in children in various aspects (Table 1). In adults, $90 \%$ occur in the small or large bowel and, the remaining $10 \%$ involve the stomach or a surgically created stoma. The single most common site is the small bowel. There have been uncommon documented cases of transpyloric prolapse of pedunculated gastric tumors. ${ }^{9}$

Most of them were benign tumors such as lipoma and inflammatory fibroid polyps. ${ }^{10} \mathrm{In}$ adults, pyloric stenosis is caused by gastric or duodenal diseases such as peptic ulcers and gastric carcinoma. Although 


\begin{tabular}{|c|c|c|}
\hline & Children & Adult \\
\hline $\begin{array}{l}\% \text { of all } \\
\text { intussusceptions }\end{array}$ & 95 & 5 \\
\hline $\begin{array}{l}\text { Cause of } \\
\text { intestinal } \\
\text { obstruction }\end{array}$ & Frequent & $\begin{array}{l}\text { Rare (5\% of } \\
\text { all intestinal } \\
\text { obstructions) }\end{array}$ \\
\hline Aetiology & $\begin{array}{l}90 \% \\
\text { idiopathic } \\
\text { (Peyer's } \\
\text { patch } \\
\text { enlargement } \\
\text { in nearly } \\
50 \% \text { ) }\end{array}$ & $\begin{array}{l}\text { Rarely } \\
\text { idiopathic. } \\
\text { Cause } \\
\text { identified in } \\
70 \%-90 \%\end{array}$ \\
\hline $\begin{array}{l}\text { Clinical } \\
\text { symptoms } \\
\text { (classic triad: } \\
\text { vomiting, rectal } \\
\text { bleeding, and } \\
\text { abdominal } \\
\text { pain) }\end{array}$ & $\begin{array}{l}\text { Usually } \\
\text { present }\end{array}$ & $\begin{array}{l}\text { Occurs in } \\
\text { only } 15 \%- \\
20 \%\end{array}$ \\
\hline Treatment & $\begin{array}{l}\text { Mainly non- } \\
\text { operative } \\
\text { (barium } \\
\text { hydrostatic } \\
\text { reduction) }\end{array}$ & $\begin{array}{l}\text { Surgical } \\
\text { resection } \\
\text { almost } \\
\text { always } \\
\text { required }\end{array}$ \\
\hline
\end{tabular}

pedunculated gastric tumors are usually benign and infrequently adenocarcinoma, they have a tendency of malignancy when they are larger than $2 \mathrm{~cm}$ in diameter. ${ }^{9}$ For the diagnosis of adult intussusception, computed tomography is now widely regarded as the modality of choice, showing a pathognomic bowel-within-bowel configuration with or without contained fat and mesenteric vessels. It can provide information regarding the location of the lesion in relation to surrounding internal organs and can characterize the leading tumor. Meanwhile, it has disadvantages, such as radiation exposure and expensive. Sonography has also been effectively used for intussusceptions, particularly in children.

It is easy to handle, suitable for real-time observation of the lesion, including intestinal peristalsis, in an emergency setting to make a correct and timely diagnosis, which is particularly important for avoiding the complications of bowel infarction and perforation secondary to high-grade obstruction. One limitation in accurate diagnosis is operator dependence. The diagnosis of adult intussusception can be delayed because it occurs infrequently, and its symptoms are long standing, intermittent, and nonspecific.

\section{Conclusion}

Gastroduodenal intussusception of a stromal tumour of the stomach is a very rare cause of gastroduodenal obstruction. Due to the CT findings, the patient was operated on successfully. This unusual case demonstrates the value of pre-operative cross-sectional imaging, particularly when there is a discrepancy between the initial first line investigations.

\section{References}

1. Bennett MK. Pathology of malignant and premalignant esophageal and gastric cancers. In: Griffin SM and Raimes SA, editors. Upper Gastrointestinal Surgery (1st edition). London, UK: WB Saunders Company Limited, 1997:1-34.

2. Van de Rijn M, Hendrickson MR, Rouse RV. CD 34 expression by gastrointestinal tract stromal tumours. Hum Pathol 1994; 25:766-71.

3. Soeda J, Makuuchi H, Shimamura K, Ohtani Y, Tanaka Y, Nakamura K, et al. A case of gastrointestinal stromal tumor of the stomach. Tokai J Exp Clin Med 1999; 24:161-7. 
4. Cohen SP, Frydman C, Zimmerman MJ, Moqtaderi F. Leiomyomatous tumours: presentation of a giant gastric leiomyoma and a review of the literature. N Y State J Med 1989; July: 416-9.

5. Pekanen P, Supromajak W, Suchato C, Suwanvilai C, Nirapathapongporin S. Gastroduodenal intussusception: a case report and literature review. J Med Assoc Thai 1988; 71:167-9.

6. Barbette P. Ouevres Chirurgiques at Anatomiques. Geneva: Francois Miege, 1674.

7. Hunter J. On introsusception (read Aug 18, 1789). In: Palmer JF, ed. The works of John Hunter, FRS London. London: Longman, Rees, Orme, Brown, Green, Longman, 1837:587-93.
8. Hutchinson J. A successful case of abdominal section for intussusception. Proc R Med Chir Soc 1873; 7:195-8.

9. Hoshi K, Takeshita K, Habu H, et al. Polypoid lesion of the stomach prolapsing into the duodenum: report of four cases and a review of literature in Japan. Stomach Intest 1980; 15:10891096.

10. Dominguez Ferreras E, Marmol Vazquez P, Telegon- Melendez A. Large inflammatory fibroid poly of the stomach. Eur J Radiol Extra 2005; 55:55-59. 